\title{
Fetal Scapular Length as a Parameter for Gestational Age
} Assessment

\author{
Dr. Kashi Nath Sarkar ${ }^{1}$, Dr. Sandip Kumar Ghosh ${ }^{2}$, Dr. Dileep Kumar Gupta ${ }^{3}$, \\ Dr. Bindu Bikash Srimani ${ }^{4}$, Dr. Runu Dhar ${ }^{5}$, Dr. Manisha Sarkar ${ }^{6}$ \\ ${ }^{I}$ (Junior Resident II, Department of Radio diagnosis, Bankura sammilani medical college, Bankura, India) \\ ${ }_{2}^{2}$ (Associate Professor, Department of Radio diagnosis, Bankura sammilani medical college, Bankura, India) \\ ${ }_{3}^{3}$ (Internee, Department of Community Medicine, Bankura sammilani medical college, Bankura, India) \\ 4,5 (Resident medical officer, Department of Radio diagnosis, Bankura sammilani medical college, Bankura) \\ ${ }^{6}$ (Junior Resident III, Department of Community Medicine, Medical College, Kolkata, India)
}

Background: An accurate estimation of fetal gestation age is pivot and pillar in management of pregnancies including high risk cases. The ossification of scapula begins at 8 weeks of gestation age and is thus easily detected on ultrasound.

Aims: To determine the correlation between fetal scapular length and gestational age and to determine its regression coefficient with respect to gestational age.

Materials and methods: A prospective observational study was conducted on 200 women aged between 18 to 35 years with normal singleton pregnancies, over a duration of 7.5 months from December 2015 to July 2016 at Bankura Sammilani Medical College. Gestational age and fetal scapular length was determined using Ultrasound machine PHILIPS HD7 (2.0.1) with 3- 5 MHz curvilinear transducer. Data was analyzed using tests of correlation and simple linear regression etc using IBM SSPS statistics 24 and MS excel.

Results: Pearson's correlation coefficient value of 0.985 and regression coefficient or slope 0.1 noted between gestational age and fetal scapular length with a significance $p<0.001$.

Conclusions: Fetal scapular length shows a positive correlation with fetal gestational age, with a steady growth rate throughout pregnancy. It also defines the normal limits of scapular length.

Keywords Correlation, regression coefficient, fetal scapular length, gestational age

\section{Introduction}

An accurate estimation of fetal gestational age is pivot and pillar in management of all pregnancies especially high risk cases. In high risk pregnancies like preeclampsia, eclampsia, gestational diabetes mellitus, central placenta previa, Rh incompatibility, intrauterine growth retardation and chronic renal disease, termination of pregnancy is inevitable once the fetus attains its maturity, in cases of any unforeseen complications. Most of the ultrasound based screening tests, biochemical tests, serological tests are being carried at a specific gestational age, during pregnancy. ${ }^{[1]}$ Expected date of delivery calculation based on last menstrual period has its own set of limitations like vague menstrual history, pregnancy during lactational amenorrhea, first trimester bleeding per vagina and irregular menstrual cycle, leading to false calculations. ${ }^{[2]}$ Symphysio fundal height in $\mathrm{cm}$ equals gestational age between 24 to 36 weeks, however a number of factor influences its measurement like gestational diabetes mellitus, multiple gestation, intrauterine growth retardation, and transverse fetal lie. ${ }^{[3]}$ Among the various biometric indices for fetal gestational age assessment, most commonly used is hadlock based composite gestational age assessment from bi parietal diameter, head circumference, abdominal circumference, and femur length. The above mentioned hadlock based fetal biometric indices shows variable results in cases of breech presentation, engaged head, macrosomia and congenital anomalies. This prospective observational study has been conducted emphasising on evaluating easily measurable scapular length as a parameter for gestational age determination, taking subjects from both second and third trimesters into account, and comparing its regression coefficient with other established biometric fetal indices for gestational age assessment. The ossification of scapula begins at 8 weeks of gestational age and is almost ossified at birth, which makes it easy to visualize on ultrasound. ${ }^{[4]}$ With this background the present study was undertaken to determine the correlation between fetal scapular length and gestational age, to determine its regression coefficient with respect to gestational age and to compare its regression coefficient with other established biometric fetal indices for gestational age assessment.

\section{Materials And Methods}

A prospective observational study was conducted among 200 women between 18 to 35 years with normal singleton pregnancies whose gestational age were confirmed by early ultrasound, over a study period of seven and a half months from December 2015 to July 2016. Study was approved by institutional ethics

DOI: 10.9790/0853-15075120124 $\quad$ www.iosrjournals.org $\quad 120 \mid$ Page


committee and consent was obtained from all study participants. Gestational ages from 18 to 39 weeks were included in study. Ultrasound was performed on PHILIPS HD7 (2.0.1) using a 3- $5 \mathrm{MHz}$ curvilinear transducer by two radiologists with ample experience and under defined scanning parameters. Radiologist one determined the average gestational age using hadlock's formula from fetal biometric indices like, abdominal circumference (AC), head circumference (HC), femur length (FL), bi parietal diameter (BPD), as well as carried out fetal anomaly scan of all cases. Radiologist two measured the scapular length. Both were unaware of the study as well its direction. Scapular length was measured on a sagittal section from acromion process of scapula to inferior angle of scapula as end point (fig $1 \& 2$ ). Standard sagittal section of measurement was ensured by taking spinous process of scapula as third reference point, which appeared in the dorsal aspect of scapula. ${ }^{[5]}$ Three reference points of measurement also prevented underestimation of scapular length by using spinous process as the superior end point. ${ }^{[5]}$ Length was measured by fixing electronic calipers at the two end points on the sagittal section showing the reference points. Three measurements were taken in centimeter and its average was recorded in data sheet for further data analysis. The scapula nearest to probe was measured.

Exclusion criteria included;

a. Oligohydramnios or polyhydramnios

b. $>90^{\text {th }}$ percentile or $<10^{\text {th }}$ percentile of estimated fetal weight as per last menstrual period

c. Chromosomal and congenital anomalies (Amelia, complete or partial duplication of scapula,

Dysplasia of scapular neck, Sprengel's deformity, congenital syphilitic osteitis of scapula, sickle shaped scapulae in Pierre Robin syndrome). ${ }^{[4]}$

d. Multiple pregnancies

e. Gross maternal obesity

f. Gestational diabetes mellitus

g. Preeclampsia

Statistical analysis was done using statistical package for social science (SPSS V 24). Pearson's correlation and regression coefficient was calculated between gestational age and scapular length as well as between gestational age and other fetal biometric indices. Significance level was considered at $\mathrm{p}$ value $<0.05$.

\section{Results}

Scapular length gives a reliable estimate of fetal gestational age. The mean scapular length was $2.69 \pm 0.58 \mathrm{~cm}$ with a range from 1.25 to $3.50 \mathrm{~cm}$. We calculated Pearson's correlation between gestational ages determined by hadlock formula with the fetal scapula length (Table 1). There was a positive correlation between mean scapula length \& gestational age determined from hadlocks based BPD, FL, AC \& HC ( $<<0.001)$. The relationship between gestational age and mean fetal scapula length is positively correlated with Pearson's correlation coefficient value of 0.985 and a significance of $p<0.001$ as shown in table 1 . Table 1 also illustrates an extremely strong correlation with other variables as well like with AC ( $\mathrm{r}=0.901)$, HC $(\mathrm{r}=0.995)$, BPD $(\mathrm{r}=$ 0.990) and FL ( $\mathrm{r}=0.983)$. Scatter plots were drawn between gestational age (independent variable) and scapula length (dependent variable) as well as gestational age with femur length, to depict the best fit line, linear regression equation, its slope and intercept (fig 3 and 4). Regression coefficient or slope of scapula is 0.1 , abdominal circumference 1.04 , head circumference 0.87 , femur length 0.22 , and bi parietal diameter 0.24 with that of gestational age (fig 3 and equation 1). Regression coefficient of scapula length with that of femur length is 0.45 (equation 2).

\section{Figures And Tables}

TABLE1: Correlation of gestational age with that of scapula length, abdominal circumference (AC), Head circumference (HC), Bi parietal diameter (BPD) and Femur length (FL)

\begin{tabular}{|c|c|c|c|c|c|c|}
\hline Variable & Test statistics & $\mathrm{AC}$ & $\mathrm{HC}$ & $\mathrm{BPD}$ & FL & SCAPULA LENGTH \\
\hline \multirow{3}{*}{ GESTATIONAL AGE } & $\begin{array}{c}\text { Pearson } \\
\text { Correlation }\end{array}$ & 0.901 & .995 & .990 & .998 & 0.985 \\
\cline { 2 - 7 } & Sig. (2-tailed) & $<0.001$ & $<0.001$ & $<0.001$ & $<0.001$ & $<0.001$ \\
\cline { 2 - 7 } & $\begin{array}{c}\text { Number of } \\
\text { subjects }\end{array}$ & 200 & 200 & 200 & 200 & 200 \\
\hline
\end{tabular}

TABLE 2: Comparison of intercept and regression coefficient of linear regression equation of scapula length (Y) with gestational age $(\mathrm{X})$ between present and past studies

\begin{tabular}{|c|c|c|c|c|c|}
\hline STUDY & $\begin{array}{c}\text { LINEAR REGRESSION } \\
\text { EQUATION }\end{array}$ & INTERCEPT & $\begin{array}{c}\text { REGRESSION } \\
\text { COEFFICIENT }\end{array}$ & $\begin{array}{c}\mathrm{p} \\
\text { value }\end{array}$ & R2 \\
\hline Present study & $\mathrm{Y}=-0.48+0.1 \mathrm{X}$ & -0.48 & 0.1 & $<0.001$ & 0.971 \\
\hline $\begin{array}{c}\text { Sherer DM, Plessinger MA, Allen } \\
\text { TAet al }\end{array}$ & $\mathrm{Y}=0.3289+0.9553 \mathrm{X}$ & 0.3289 & 0.9553 & $<0.001$ & 0.942 \\
\hline${\text { Murao et } \mathrm{al}^{[7]}}^{\mathrm{T}}$ & $\mathrm{Y}=0.3455+0.6847 \mathrm{X}$ & 0.3455 & 0.6847 & $<0.001$ & 0.90 \\
\hline
\end{tabular}


Table 3: Scapular length (Mean $\pm 1.96 \mathrm{SD})$ predicted by gestational age calculated on the basis of linear regression equation $\mathrm{Y}=-0.48+0.1 \mathrm{X}$, where $\mathrm{Y}$ is scapula length, $\mathrm{X}$ is gestational age, -0.48 is intercept and 0.1

\begin{tabular}{|c|c|c|c|}
\hline \multirow[t]{2}{*}{ GESTATIONAL AGE (WEEKS) } & \multicolumn{3}{|c|}{ SCAPULAR LENGTH $(\mathrm{cm})$} \\
\hline & $-1.96 \mathrm{SD}(\mathrm{SD}=0.5735)$ & MEAN & $+1.96 \mathrm{SD}^{*}$ \\
\hline 18 & 0.21 & 1.33 & 2.46 \\
\hline 19 & 0.31 & 1.43 & 2.56 \\
\hline 20 & 0.41 & 1.54 & 2.66 \\
\hline 21 & 0.51 & 1.64 & 2.76 \\
\hline 22 & 0.61 & 1.74 & 2.86 \\
\hline 23 & 0.71 & 1.84 & 2.96 \\
\hline 24 & 0.82 & 1.94 & 3.06 \\
\hline 25 & 0.92 & 2.04 & 3.16 \\
\hline 26 & 1.02 & 2.14 & 3.26 \\
\hline 27 & 1.12 & 2.24 & 3.37 \\
\hline 28 & 1.22 & 2.34 & 3.47 \\
\hline 29 & 1.32 & 2.44 & 3.57 \\
\hline 30 & 1.42 & 2.55 & 3.67 \\
\hline 31 & 1.52 & 2.65 & 3.77 \\
\hline 32 & 1.62 & 2.75 & 3.87 \\
\hline 33 & 1.75 & 2.88 & 4.00 \\
\hline 34 & 1.83 & 2.95 & 4.07 \\
\hline 35 & 1.93 & 3.05 & 4.17 \\
\hline 36 & 2.03 & 3.15 & 4.27 \\
\hline 37 & 2.13 & 3.25 & 4.38 \\
\hline 38 & 2.23 & 3.35 & 4.48 \\
\hline 39 & 2.33 & 3.45 & 4.58 \\
\hline
\end{tabular}

$\mathrm{SD}=0.5735$

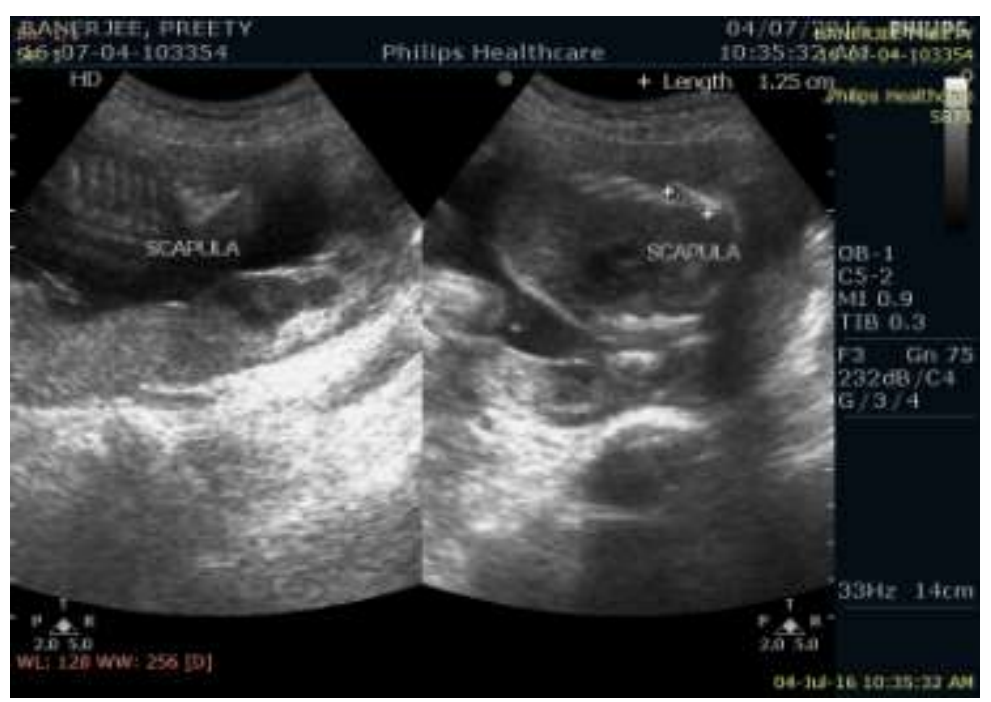

Fig 1: Sagittal ultrasound scans of fetus with cephalic presentation showing acromion process, spinous process and inferior angle of scapula. Scapular length measures $1.25 \mathrm{~cm}$ from tip of acromion process to inferior angle of scapula, corresponding to approximately 18 weeks of gestational age. End points depicted in plus (+) sign of electronic calipers. 


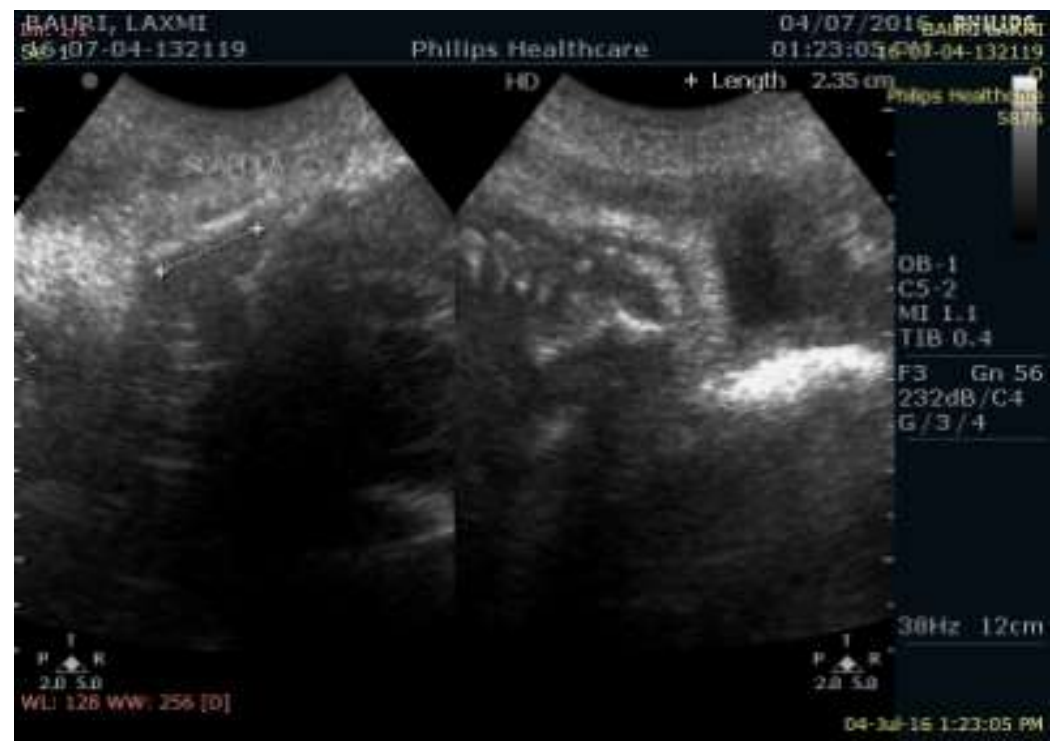

Fig 2: Sagittal ultrasound scans of fetus with scapula measuring $2.35 \mathrm{~cm}$ from tip of acromion process to inferior angle of scapula, corresponding to approximately 26 weeks of gestational age. End points depicted in plus (+) sign of electronic calipers.

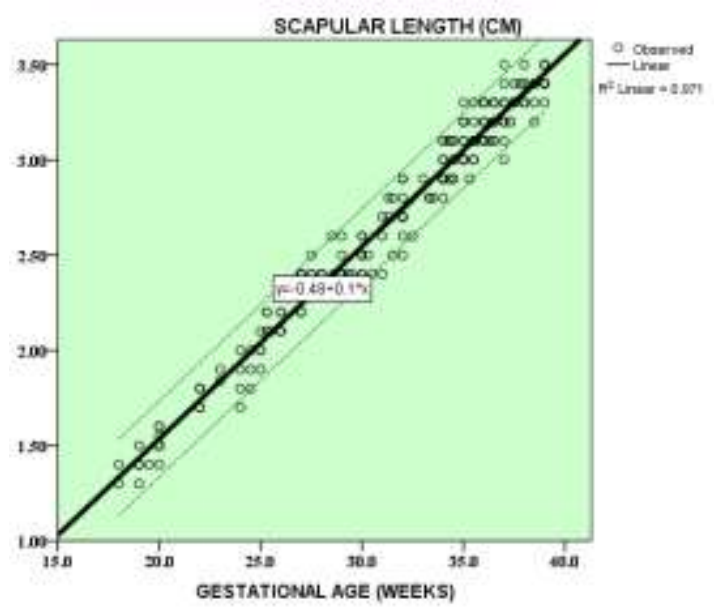

Fig 3 Scatter plot between dependent variable scapula length(Y) and independent variable gestation age (X) showing bold best fit line with a linear regression equation of $\mathrm{Y}=-0.48+0.1 \mathrm{X}$ and dotted interpolation line on either side, where -0.48 is the intercept and 0.1 is the regression coefficient.

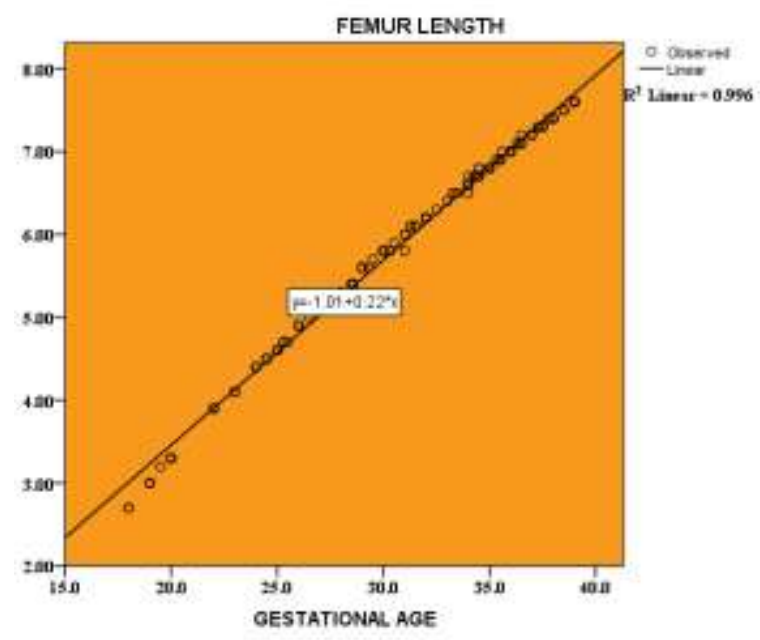


Fig 4: Scatter plot between independent variable gestational age in weeks $(X)$ and dependent variable femur length in $\mathrm{cm}(\mathrm{Y})$, showing the best fit line with a linear regression equation of $\mathrm{Y}=1.01+0.22 \mathrm{X}$, where 1.01 is the intercept and 0.22 is the slope of regression coefficient.

\section{Indentations And Equations}

Linear regression equation between dependent variable scapula length $(\mathrm{Y})$ and independent variable gestation age $(\mathrm{X})$ Equation 1: $\mathrm{Y}=-0.48+0.1 \mathrm{X}$ where -0.48 is the intercept and 0.1 is the regression coefficient. Linear regression equation between dependent variable scapula length $(\mathrm{Y})$ and independent variable femur length $(\mathrm{X})$ Equation 2: $\mathrm{Y}=0.02+0.45 \mathrm{X}$ where 0.02 is the intercept and 0.45 is the regression coefficient.

\section{Discussion}

Estimation of an accurate gestational age is vital for management of pregnancies. It has been emphasized since long for fetal biometric indices, which are accurate, easy to calculate with hassle free interpretation and reproducible. Fetal scapula is consistently and easily identifiable on ultrasound and gives us a reproducible plane for measurement. ${ }^{[6]}$ The ossification of scapula begins at 8 weeks of gestation age and is almost completed by birth. ${ }^{[4]}$ With evolution, the supraspinatous fossa became smaller whereas infraspinatous fossa became larger due to changes in shoulder elevator muscle force couples. ${ }^{[8]}$ This study shall prove its worth in cases of engaged fetal head, where it is difficult to measure fetal bi parietal diameter and head circumference as well as in cases of intrauterine growth retardation, macrosomia and malformation where abdominal circumference measurement gives false values. In above enlisted clinical scenarios measurement of fetal scapular length shall give an accurate, reproducible, hassle free estimation of fetal gestational age. We compared the intercept and regression coefficient (slope) between previous and present study as illustrated in table 2 . In present study done on 200 pregnant mothers we got a linear regression equation $\mathrm{Y}=-0.48+0.1 \mathrm{X}$ (equation 1 ) and pearson's correlation coeficient of 0.985 as compared to Sherer DM, Plessinger MA, Allen TA et al ${ }^{[6]}$ done on 515 singleton fetus with a linear regression equation of $\mathrm{Y}=0.3289+0.9553 \mathrm{X}$ and $\mathrm{R} 2$ of 0.942 . Our study showed comparatively stronger correlation between gestational age and scapular length in comparison to both the studies of Sherer DM, Plessinger MA, Allen TA et al ${ }^{[6]}$ and Munro et al ${ }^{[7]}$ done previously. In future an average gestational can be computed by taking all biometric indices into account including scapula length. Scapula outline delineation may be cumbersome in case of maternal obesity. ${ }^{[6,9,10]}$

\section{Acknowledgements}

The authors hereby acknowledges Dr Tapan Dhibar (professor), Dr. Jayati Bardhan (Associate Professor), Dr Debasis Deoghuria (Associate Professor), Dr Sumanta Kumar Mandal(Associate Professor), Dr Rikta mallik (Assistant Professor) for their extensive support, Dr Debashish nandi, Dr Somnath paul, Dr Koushik Sarkar, Dr Samik Ghosh, Dr. Sweta Singh and last but not the least the pregnant mothers themselves who were all extremely pivotal and cooperative throughout the study period.

\section{Journal Papers:}

\section{References}

[1] Pernoll ML, Taylor CM. Normal pregnancy and prenatal care. In: Decherney AH, Pernoll ML (Eds). Current Obstetric and Gynecologic Diagnosis and Treatment. $8^{\text {th }}$ ed. Fast Norwalk: Appleton and Lange, 1994: pp. 183-201

[2] Grudzinskas JG. Assessment of fetal wellbeing in early pregnancy. In: Edmonds Dk (ed). Dewhurst's Textbook of Obstetrics and Gynaecology for postgraduates. $6^{\text {th }} \mathrm{ed}$. Blackwell science Ltd. 1999: pp. 133-8.

[3] Hadlock FP, Harrist RB, Hohler CW Determination of fetal age. In: Athey PA, Hadlock FP (eds).Ultrasound in Obstetrics and Gynaecology, 2nd ed. New Delhi: B.I. Churchill Livingstone Pvt. Ltd., 1985: pp. 22-37.

[4] McClure, James G. M.D.; Raney, R Beverly M.D. Anomalies of the Scapula.Clinical Orthopaedics \& Related Research. 1975 Jul/Aug;110:22-31

[5] Jeanty, P. Fetal biometry. in: AC Fleischer, R Romero, F Manning, P Jeanty, AE James Jr (Eds.) The principles and practice of ultrasonography in obstetrics and gynecology. 4th ed. Appleton \& Lange, Norwalk; 1991:93-108.

[6] Sherer DM, Plessinger MA, Allen TA. Fetal scapular length in the ultrasonographic assessment of gestational age. J Ultrasound Med. 1994 Jul;13(7):523-8

[7] Murao F, Shibukawa T, Takamiya O, Yamamoto K, Hasegawa K, Antenatal Measurement of Scapula Length Using Ultrasound. Gynecol Obstet Invest 1989;28:195-197

[8] Samilson RL. Congenital and developmental anomalies of the shoulder girdle. Orthop Clin North Am. 1980 Apr;11(2):219-31.

[9] Cohen HL. Cooper J, Eisenberg P, Mandle FS, Gross BR, Goldman MA, et al. Normal length of fetal kidneys: Sonographic study in 397 obstetric patients. Am J Radiol 1991; 154: 545-8.

[10] Ansari SM, Saha M, Paul AK. Mia SR, Sohel A, Karim R. Ultrasonographic study of 793 fetuses: Measurement of normal kidney lengths in Bangladesh. Aust Radio 1997; 41: 3-5. 